\title{
Removal of As (III) from Aqueous Solutions Using Montmorillonite
}

\author{
Ansar Anjum, Punnuswamy Lokeswari, Manpreet Kaur, Monika Datta
}

Department of Chemistry, University of Delhi, Delhi, India.

Email: monikadatta_chem@yahoo.co.in

Received September $6^{\text {th }}, 2011$; revised October $26^{\text {th }}, 2011$; accepted November $11^{\text {th }}, 2011$.

\begin{abstract}
Arsenic (III) adsorption has been studied as a function of concentration of arsenic (III) in the solution, pH of the solution, contact time during the batch extraction process using montmorillonite (MMT) and surfactant modified MMT (CPC-MMT and CTAB-MMT) from aqueous solution It has been observed that up to $90 \%$ of arsenic (III) can be extracted from a solution containing $100 \mathrm{ppm}$ of As (III) at pH 8.0, within a contact time of 10 minutes. The lowest level of As (III) that could be extracted was found to be $0.4 \mathrm{ppm}$.
\end{abstract}

Keywords: Arsenic (III), MMT, Surfactant Modified MMT, Adsorption Isotherm

\section{Introduction}

Arsenic, cadmium, chromium, cobalt, copper, lead, manganese, mercury, nickel and zinc, etc. are the metals of major environmental concern in the present day world. Arsenic has been classified as one of the most toxic and carcinogenic metal and has therefore been recorded by the World Health Organization as a first priority issue [1].

Arsenic is ubiquitous and ranks 20th in natural abundance, comprising about $0.00005 \%$ of the earth's crust. Most environmental problems are due to the mobilization of arsenic under natural conditions (natural weathering reactions, biological activity, geochemical reactions, volcanic emissions and other anthropogenic activities).

Arsenic is known to exist in various oxidation states as arsenious acids, arsenic acids, arsenites, arsenates, methylarsenic acid, dimethylarsinic acid, etc., in water Two forms that are commonly found in natural water are arsenite $\left(\mathrm{AsO}_{3}^{3-}\right)$, As (III) and arsenate $\left(\mathrm{AsO}_{4}^{3-}\right)$, As (V). Arsenic (V) dominates in oxic water, while arsenic (III) is more likely to occur in anoxic water [2]. Of both the forms As (III) is known to be more toxic than As (V) and is predominant in ground waters [3].

The occurrence of arsenic in natural water is a worldwide problem. Arsenic pollution has been reported in the Argentina, Bangladesh, Canada, China, India, Japan, Mexico, New Zealand, Taiwan and USA. Fifty districts of Bangladesh and nine in West Bengal (India) have been reported to have the concentration of arsenic above the World Health Organization's arsenic guideline value of
$10 \mathrm{mg} \cdot \mathrm{L}^{-1}[4,5]$ in the drinking water.

Prolonged consumption of water containing arsenic is known to produce long term health effects, including dermal changes and respiratory, cardiovascular, gastrointestinal, genotoxic, mutagenic, and carcinogenic effects [6]. Long term exposure to arsenic via drinking water causes skin, lung, bladder, and kidney cancer, skin thickening (hyperkeratosis) neurological disorders, muscular weakness, loss of appetite, and nausea.

Various methods that have been reported for the removal of arsenic from aqueous solutions include coagulation and flocculation, precipitation, adsorption and ion exchange, membrane filtration, ozone oxidation, bioremediation and electrochemical treatments. Most of these methods involve production of high arsenic contaminated sludge [7], high maintenance cost and require relatively expensive mineral adsorbents which offset performance and efficiency advantages [8].

Of all the methods adsorption has been most extensively used as reported by Abhijit and Sunando [9]. As cited by Deliyanni, Peleka and Matis [10] selective adsorption utilizing biological materials, mineral oxides, clay minerals, zeolites, fly ash, activated carbons, or polymer resins, has generated increasing interest. In the present work, montmorillonite (a member of the smectite group of the clay mineral) has been selected as the host material for the removal of arsenic from aqueous solutions. MMT is known for its low cost, high surface area, high chemical stability, high sorption properties and rich intercalation chemistry. To the best of our knowledge, the best result 
achieved so far accounts for the detection of $10 \mathrm{ppm}$ of arsenic using montmorillonite [1].

\section{Experimental}

\subsection{Materials and Methods}

Montmorillonite (MMT-KSF) was obtained from Sigma Aldrich (USA). Cetylpyridinium chloride (CPC) and cetyl trimethylammonium bromide (CTAB) were obtained from Merck (Germany) and British Drug House respectively. Arsenious oxide and potassium antimonyl tartarate were obtained from British Drug House (England), Sodium hydroxide; hydrochloric acid and potassium iodate were obtained from Qualingens (India). Leuco crystal violet (LCV) was obtained from Sigma Aldrich Pvt. Ltd. (Germany).The AR grade chemicals/reagents and double distilled water was used throughout the experiment.

\subsection{Synthesis of Organoclay}

Surfactant modified clay (CPC-MMT and CTAB-MMT) were synthesized by the modification of the reported procedures by Khalaf, Bouras and Perrichon [11].

In order to facilitate intercalation, $5.0 \mathrm{~g}$ of dried $\left(80^{\circ} \mathrm{C}\right)$ MMT was dispersed in $250 \mathrm{ml}$ of double distilled water and was kept under constant stirring for a period of 24 hours. To this $1 \%$ aqueous surfactant (CPC and CTAB) solution was gradually added with constant stirring over a period of 3 hours at NTP. The clay suspension was separated by centrifugation and washed with double distilled water for the complete removal of unreacted surfactant. The resies thus obtained were dried at $80^{\circ} \mathrm{C}$ and was labelled as CPC-MMT and CTAB-MMT.

\subsection{Characterization}

X-ray diffractograms were recorded on X-ray Diffractoter (Philips PW3710) using $\mathrm{CuK} \alpha$ radiations. The specific surface areas were measured by adsorption of nitrogen according to the BET method. UV-VIS studies were perrmed on Systronics UV/VIS spectrophotometer. $\mathrm{pH}$ was monitored using a pH meter (Eutech instruments, $\mathrm{pH}$ 510).

\subsection{Experimental}

\subsubsection{Preparation of As (III) Solution}

As (III) stock solution $(1000 \mathrm{mg} / \mathrm{L})$ was repared by dislving $1.320 \mathrm{~g}$ of arsenious oxide $\left(\mathrm{As}_{2} \mathrm{O}_{3}\right)$ in $25 \mathrm{~mL}$ of 1 $\mathrm{M} \mathrm{NaOH}$ in double distilled water. The solution was then diluted to about $100 \mathrm{~mL}$ with double distilled water and two drops of $0.2 \%$ phenolphthalein was added to this solution followed by neutralization of the solution using $1 \mathrm{M} \mathrm{HCl}$. The volume of the solution was made up to $1 \mathrm{~L}$ in a vometric standard flask.

\subsubsection{Spectrophotometric Determination of As (III)}

The concentration of arsenic (III) was determined spec- trophotometrically procedure using LCV as reported [12].

The reagent blank gave negligible absorbance at the above wavelength. A rectilinear calibration graph was obined by measuring the absorbance of the solution at 592 mover a known concentration range and concentration of As (III) in the experimental solution was calculated from the calibration curve.

\subsubsection{Behavior of As (III) Adsorption on Clay and Modified Clay}

The adsorption experiments were carried out using MMT and CPC-MMT and CTAB-MMT as an adsorbent. The batch experiments were carried out with $0.1 \mathrm{~g}$ of the adsorbent and $50 \mathrm{~mL}$ of (100 ppm) As (III) solution, as a function of $\mathrm{pH}$, contact time and concentration. The concentration of arsenic in the supernatant was estimated spectrophotometrically. The percentage of the metal adsorbed onto the adsorbent was calculated using the relation:

$$
\% \text { As (III) adsorbed }=\left[\left(\mathrm{C}_{\mathrm{i}}-\mathrm{C}_{\mathrm{e}}\right) / \mathrm{C}_{\mathrm{i}}\right] * 100
$$

Amount of metal adsorbed $\left(\mathrm{q}_{\mathrm{e}}\right)$ was calculated from the relationship

$$
\mathrm{q}_{\mathrm{e}}=\left\{\left(\mathrm{C}_{\mathrm{i}}-\mathrm{C}_{\mathrm{e}}\right) * \mathrm{~V}\right\} / \mathrm{m}
$$

where $\mathrm{C}_{\mathrm{i}}$ was the initial As (III) concentration (mg/L), $\mathrm{C}_{\mathrm{e}}$ was the final concentration of As (III) in the solution after equilibrium was attained $(\mathrm{mg} / \mathrm{L}), \mathrm{V}$ was the volume of the As (III) solution (L) and $m$ was the mass of the adsorbent (g) used.

\section{Results and Discussions}

\subsection{XRD Analysis}

The X-ray diffraction pattern of the clay and the organo clay is shown in Figure 1. The decrease in the 2 theta value with respect to MMT was observed in case of CPCMMT and CTAB-MMT. The interlayer $\left(\mathrm{d}_{001}\right)$ spacing of MMT, CPC-MMT and CTAB-MMT is $12 \AA, 19.5 \AA$ and

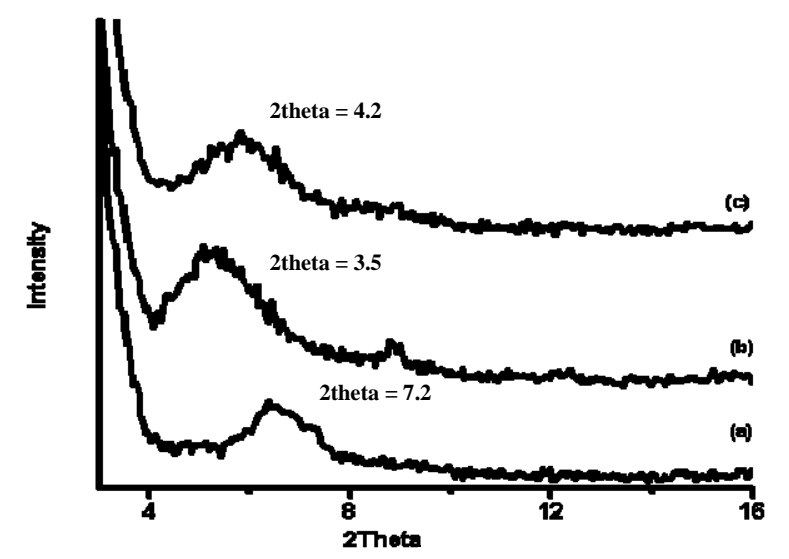

Figure 1. XRD pattern of (a) MMT; (b) CTAB-MMT; (c) CPC-MMT. 
17.6 ̊ respectively. The increase in d spacing of CPCMMT and CTAB-MMT with respect to MMT is $7.5 \AA$ and $5.6 \AA$ respectively. This increase in the basal spacing is attributed to intercalation of the surfactants into the interlayer region of the host clay, MMT.

Generally, there are two most important mechanisms of the cationic surfactant adsorption on solids: 1) ion exchange and 2) hydrophobic interactions [13]. Thus, there are two well-distinguished phases of CPC and CTAB adsorption on MMT, first can be ascribed to incomplete monolayer formation. After the monolayer onset of the surfactant is completed bilayers are formed. The CPC adsorption arrangements are illustrated in Figure (2). Figures 2(a)-(c) illustrates the $\mathrm{CPC}$ adsorption on external MMT surface and Figures 2(d) and (e) simply manifest the intercalation, as also observed by the X-ray diffracttion analysis. Similar adsorption mechanism is also followed by the CTAB on MMT surface. The alkyl ammonium bilayer structure (Figure 2(c)) is positively charged, which makes possible the adsorption of arsenite ions [14].

\subsection{Surface Area Analysis}

The Nitrogen BET adsorption method indicates that the surface area of MMT, CPC-MMT and CTAB-MMT are $28,700 \mathrm{~cm}^{2} / \mathrm{g}, 82,000 \mathrm{~cm}^{2} / \mathrm{g}$ and $98,200 \mathrm{~cm}^{2} / \mathrm{g}$, respectively. This increase in surface area of CPC-MMT and CTAB-MMT clays with respect to MMT is $53,000 \mathrm{~cm}^{2} / \mathrm{g}$ and $69,500 \mathrm{~cm}^{2} / \mathrm{g}$ respectively. The increase in surface area is due to an increase in the interlayer spacing.

\subsection{Effect of $\mathbf{p H}$ on As (III) Adsorption}

The effect of $\mathrm{pH}$ on the amount of arsenic uptake by clay and organo clay (CPC-MMT and CTAB-MMT) was studied in the $\mathrm{pH}$ range of $1-12$, using 0.1 gram of the adsorbent and $100 \mathrm{ppm}$ at As (III) solution with contact time of 60 minutes (Figure 3).

The percentage of As (III) adsorbed increased from $47.5 \%(23.5 \mathrm{mg} / \mathrm{g})$ to $70.25 \%(35.15 \mathrm{mg} / \mathrm{g})$ in the $\mathrm{pH}$ range of $1-8$, and then decreased to $56.88 \%(28.45 \mathrm{mg} / \mathrm{g})$ at $\mathrm{pH}$ 12 in MMT. A similar behaviour was observed for CPCMMT and CTAB-MMT where the percentage of As (III) adsorbed in the $\mathrm{pH}$ range of $1-8$, increased from $89 \%$ $(44.5 \mathrm{mg} / \mathrm{g})$ to $94.4 \%(47.20 \mathrm{mg} / \mathrm{g})$ in case of CPC-MMT and $88 \%(44 \mathrm{mg} / \mathrm{g})$ to $92.6 \%(46.32 \mathrm{mg} / \mathrm{g})$ in case of CTAB-MMT, followed by a decrease in As (III) adsorption up to $\mathrm{pH} 12$ in both the cases.
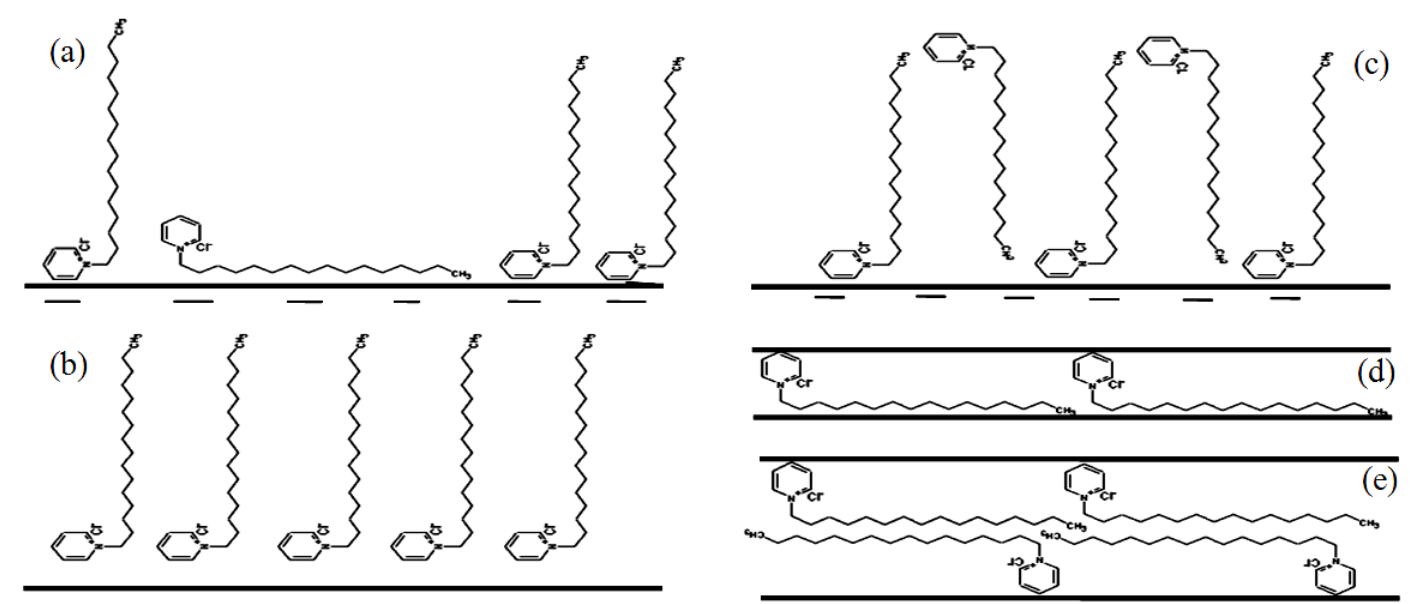

Figure 2. Arrangement of CPC adsorbed onto MMT (a) incomplete monolayer (b) monolayer (c) bilayer (d) monolayer intercalated (e) bilayer intercalated.
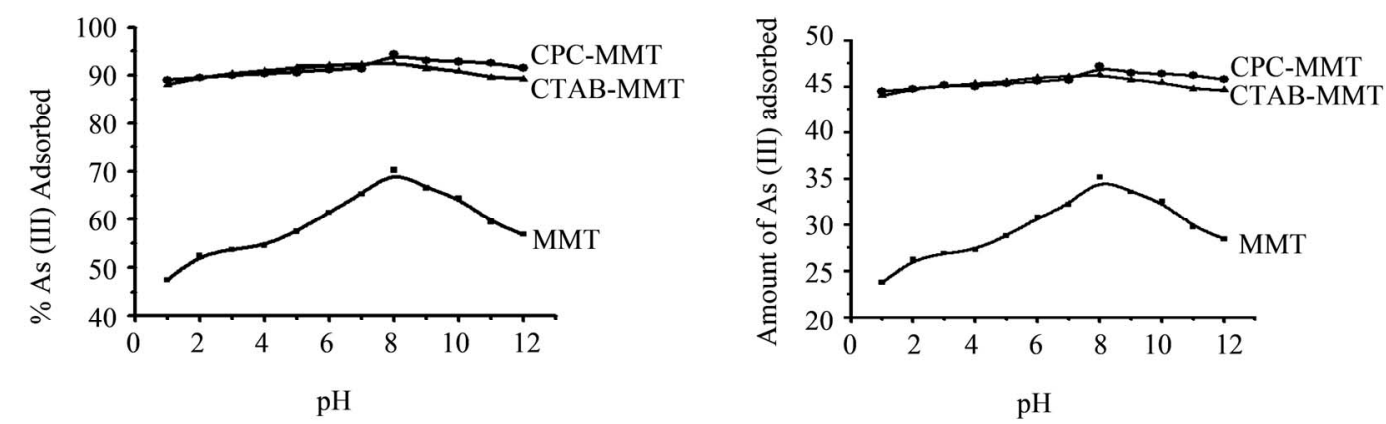

Figure 3. Adsorption as a function of pH. Conc. of As (III) solution = $100 \mathrm{ppm}$, mass of adsorbent = $0.1 \mathrm{gm}$, pH 1 - 12 , contact time $=60$ minutes. 
These results show that in a highly acidic medium, where the adsorbent surfaces are highly protonated and As (III) mainly exists in the form of neutral $\mathrm{H}_{3} \mathrm{AsO}_{3}$ species, adsorption of As (III) is not favorable. This is due to the weak interaction that occurs between the adsorbent and $\mathrm{H}_{3} \mathrm{AsO}_{3}$. Therefore, the only driving force between $\mathrm{H}_{3} \mathrm{AsO}_{3}$ and the adsorbent is the physical adsorption, thereby resulting in less adsorption. At near neutral $\mathrm{pH}$ values (7 - 9), slow dissociation of $\mathrm{H}_{3} \mathrm{AsO}_{3}$ producing arsenite ions begins and it reaches a maximum at $\mathrm{pH}$ 8.0. These partially neutral and partially negatively charged arsenite ions are attracted to the positively charged surface of the adsorbent thereby resulting in high As (III) uptake by the adsorbent in this $\mathrm{pH}$ range. At $\mathrm{pH} 10$ and above, the adsorbent surfaces become negatively charged. Hence, the interaction between the adsorbent and arsenite ions decreases leading to low As (III) uptake by the adsorbent.

The As (III) uptake by CPC-MMT and CTAB-MMT was observed to be higher than MMT. This is because, the surface of the organo clay composites is highly positively charged than MMT, as indicated by the zeta potential values $(\mathrm{MMT}=12.9 \mathrm{mV}, \mathrm{CPC}-\mathrm{MMT}=17.2 \mathrm{mV}$, CTAB-MMT $=22.6 \mathrm{mV}$ ). This in turn facilitates stronger interaction between the positively charged clay surface and the existing species of arsenite ions in the solution, thereby leading to a higher As (III) uptake.

Therefore $\mathrm{pH}(8.0)$ was fixed as the $\mathrm{pH}$ at which maximum As (III) adsorption on the clay and organoclay had occurred.

\subsection{Effect of Contact Time on As (III) Adsorption}

The effect of contact time on the amount of arsenic uptake

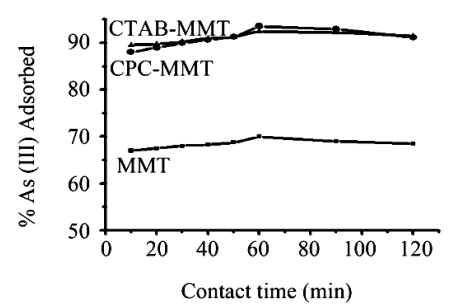

by clay (MMT) and organoclay (CPC-MMT and CTABMMT) was studied as a function of time in the range of 10 120 minutes, using 0.1 gram of the adsorbent, at $\mathrm{pH} 8.0$ with initial concentration of As (III) at100 ppm (Figure 4).

The percentage of As (III) adsorbed increased from $67 \%(33.5 \mathrm{mg} / \mathrm{g})$ at 10 minutes to $70 \%(35 \mathrm{mg} / \mathrm{g})$ at 60 minutes on MMT and decreases thereafter. A similar behaviour was observed for CPC-MMT and CTAB-MMT where the percentage of As (III) adsorbed increased from $88 \%(44 \mathrm{mg} / \mathrm{g})$ at 10 minutes to $94 \%(47.44 \mathrm{mg} / \mathrm{g})$ at 60 minutes in the former and $89 \%(44.75 \mathrm{mg} / \mathrm{g})$ at $10 \mathrm{~min}-$ utes to $92.5 \%(46.25 \mathrm{mg} / \mathrm{g})$ at 60 minutes in the latter.

The adsorption of As (III) on the clay and organoclay occurred very quickly in the initial phase of the experiment. This could be due to the availability of a large number of adsorption sites on the clay surface. Maximum adsorption of the As (III) was observed in the time duration of 60 minutes and beyond this no further increase in adsorption was observed. Therefore, 60 minutes was fixed as the time at which maximum As (III) adsorption on the clay and modified clay had occurred.

\subsection{Effect of Initial Concentration on As (III) Adsorption}

The effect of initial concentration on the amount of arsenic uptake by clay (MMT) and organoclay (CPC-MMT and CTAB-MMT) was studied using 0.1 gram of the adsorbent and by varying the concentration of As (III) solution from 0.2 - $100 \mathrm{ppm}$ and maintaining $\mathrm{pH} 8.0$ and a contact time of 60 minutes. (Figure 5)

An increase in the percentage of As (III) adsorbed was observed from $24 \%$ to $71 \%$ in MMT on varying the metal

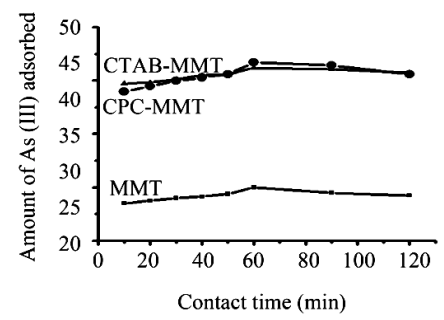

Figure 4. Adsorption as a function of contact time. Conc. of As (III) solution = $100 \mathrm{ppm}$, mass of adsorbent $=\mathbf{0 . 1} \mathrm{gm}$, $\mathrm{pH} 8.0$, contact time $=10-120$ minutes.
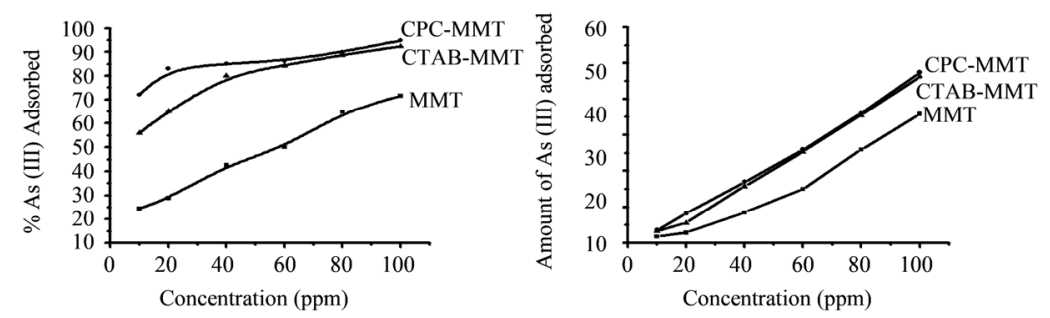

Figure 5. Adsorption as a function of As (III) concentration. Conc. of As (III) solution = $10 \mathrm{ppm}-100 \mathrm{ppm}$, mass of adsorbent $=0.1 \mathrm{gm}, \mathrm{pH} \mathrm{8.0}$, contact time $=60$ minutes. 
concentration from 10 - $100 \mathrm{ppm}$. The percentage of As (III) adsorbed increased from $21 \%$ to $94.4 \%$ in CPC-MMT and $21 \%$ to $92.3 \%$ in CTAB-MMT on varying the metal concentration from $0.2-100 \mathrm{ppm}$. The amount of As (III) adsorbed increased from $0.066 \mathrm{mg} / \mathrm{g}$ to $47.43 \mathrm{mg} / \mathrm{g}$ in case of CPC-MMT and $0.065 \mathrm{mg} / \mathrm{g}$ to $46.25 \mathrm{mg} / \mathrm{g}$ in CTABMMT composites. Whereas, in case of MMT the amount of As (III) adsorbed increases from $1.85 \mathrm{mg} / \mathrm{g}$ to 35.75 $\mathrm{mg} / \mathrm{g}$ on varying concentration from $10-100 \mathrm{ppm}$.

The increase in As (III) adsorption on all the three adsorbents in the given concentration range indicates a heterogeneous system where adsorption is not restricted to monolayer formation. The percentage of As (III) adsorbed in case of surfactant organoclay was observed to be higher than that of the host clay. This can be explained on the basis of zeta potential studies. The zeta potential values of CPC-MMT and CTAB-MMT were found to be +22.6 $\mathrm{mV}$ and $+17.2 \mathrm{mV}$ respectively. The zeta potential values suggest that the adsorption is therefore due to the electrostatic attraction between the positively charged adsorbent (organoclay) and the negatively charged adsorbate (arsenite). In case of MMT, the zeta potential value is +12.9 $\mathrm{mV}$ and is therefore less positively charged as compared to CPC-MMT and CTAB-MMT. Therefore, the interacttion between the adsorbent and arsenite ions is less, thereby leading to a low uptake.

\subsection{Adsorption Isotherms}

The Freundlich isotherm is one of the widely used mathematical descriptions and it usually fits the experimental data over a wide range of concentrations. This isotherm gives an expression encompassing the surface heterogeneity and the exponential distribution of active sites and their energies. It describes a heterogeneous system and reversible adsorption process that is not restricted to the monolayer formation. This model predicts that adsorption of arsenic on the organoclay increases with increase in arsenic concentration in the solution.

The Freundlich equation is as follows: $\mathrm{q}_{\mathrm{e}}=\mathrm{K}_{\mathrm{f}} \mathrm{C}_{\mathrm{e}}^{1 / \mathrm{n}}$

The linear form of the above equation is given as:

$$
\log \mathrm{q}_{\mathrm{e}}=\log \mathrm{K}_{\mathrm{f}}+1 / \mathrm{n} \log \mathrm{C}_{\mathrm{e}}
$$

where $K_{f}$ is the Freundlich constant $(\mathrm{mg} / \mathrm{g}$ ) and $1 / \mathrm{n}$ is the heterogeneity factor. A plot of $\log \mathrm{q}_{\mathrm{e}}$ and $\log \mathrm{C}_{\mathrm{e}}$ gives a straight line and the values of $\mathrm{K}_{\mathrm{f}}$ and $\mathrm{n}$ can be calculated from the intercept and slope of the plots respectively (Figure 6).

The linear equation obtained for CPC-MMT and CTAB-MMT were $\mathrm{y}=1.25689 \mathrm{x}+1.67829\left(\mathrm{R}^{2}=0.9992\right)$ and $y=1.48656 x+1.66462\left(R^{2}=0.9951\right)$ respectively. The $K_{f}$ values obtained from the equation were $47.74 \mathrm{mg} / \mathrm{g}$ and $46.19 \mathrm{mg} / \mathrm{g}$ respectively.

The value of $\mathrm{n}$ obtained from the above equation was 0.7956 and 0.6727 respectively. These values indicate a favorable adsorption process.

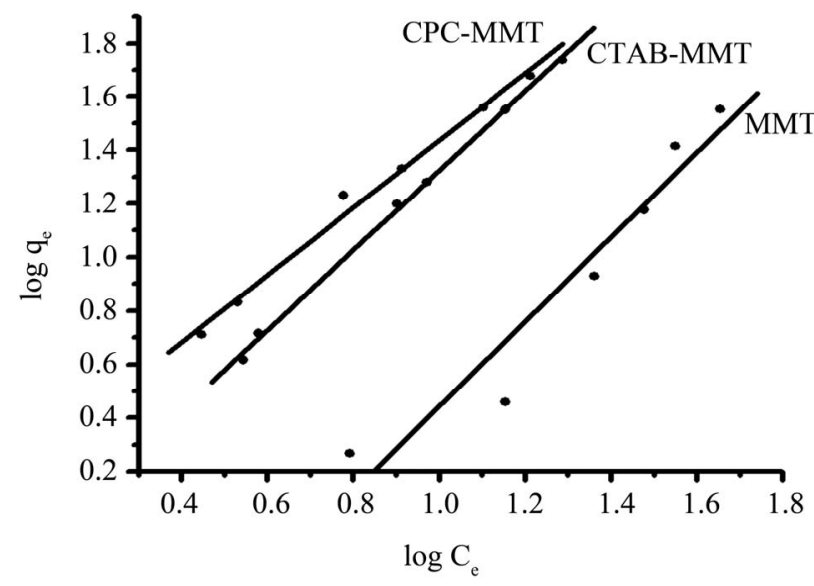

Figure 6. Freundlich plot for the adsorption of As (III) on MMT, CPC-MMT and CTAB-MMT.

\section{Conclusions}

The results obtained indicate that the maximum As (III) uptake on MMT, CPC-MMT and CTAB-MMT was found to be $35.75 \mathrm{mg} / \mathrm{g}(71 \%), 47.43 \mathrm{mg} / \mathrm{g}(95 \%)$ and $46.15 \mathrm{mg} / \mathrm{g}$ $(92 \%)$ respectively. The adsorption capacity of CPCMMT and CTAB-MMT was observed to be higher than that of MMT. This is because of the higher positively charged organoclay surface which facilitates stronger interaction between the adsorbent and the adsorbate, thereby leading to a higher As (III) uptake. The lowest level of detection of As (III) from aqueous solutions was found to be 0.4 ppm using both the clay composites (CPC-MMT and CTAB-MMT). This process was found to be highly effective over a wide range of concentration and $\mathrm{pH}$. Thus, these composites can be successfully employed for the removal of As (III) from aqueous solutions.

\section{REFERENCES}

[1] A. Ramesh, H. Hasegawa, T. Maki and K. Ueda, “Adsorption of Arsenic from Aqueous Solutions by Polymeric A1/Fe Modified Montmorillonite," Separation and Purification Technology, Vol. 56, No. 1, 2007, pp. 90100. doi:10.1016/i.seppur.2007.01.025

[2] Md. M. Rahman, Y. Seike and M. Okumara, "Concentrations of Arsenic in Brackish Lake Water: Application of Tristimulus Colorimetric Determination," The Japan Society for Analytical Chemistry, Vol. 22, No. 3, 2006, p. 475.

[3] P. Sharma, "Sequential Trace Determination Arsenic (V) by Differential Pulse of Arsenic (III)," Analytical Sciences, Vol. 11, No. 2, 1995, pp. 261-262. doi:10.2116/analsci.11.261

[4] Md. J. Haron, F. A. Rahim, A. H. Abdullah, M. Z. Hussein and A. Kassim, "Sorption Removal of Arsenic by Cerium-Exchanged Zeolite P," Materials Science and Engineering B, Vol. 149, No. 2, 2008, pp. 204-208. 


\section{doi:10.1016/i.mseb.2007.11.028}

[5] P. Mohanty, C. B. Majumder and B. Mohanty, "Laboratory Based Approaches for Arsenic Remediation from Contaminated Water: Recent Developments," Journal of Hazardous materials, Vol. 137, No. 1, 2006, pp. 464-479. doi:10.1016/j.jhazmat.2006.02.023

[6] X. Dai, O. Nekrassova, M. E. Hyde and R. G. Compton, "Anodic Stripping Voltammetry of Arsenic (III) Using Gold Nanoparticle-Modified Electrodes," Analytical Chemistry, Vol. 76, No. 19, 2004, pp.5924-5929.

http://www.who.int/inf-fs/en/fact210.html. (1993)

[7] N. Haque, G. Morrison, I. C.-A. Jorge and L. GardeaTorresday, "Iron Modified Light Expanded Clay Aggregates for the Removal of Arsenic (V) from Ground Water," Microchemical Journal, Vol. 88, No. 1, 2008, pp. 7-13. doi:10.1016/j.microc.2007.08.004

[8] A. Maiti, S. D. Gupta, J. K. Basu and S. De, "Adsorption of Arsenite Using Natural Laterite As Adsorbent," Separation and Purification Technology, Vol. 55, No. 3, 2007, pp. 350-359. doi:10.1016/j.seppur.2007.01.003
[9] E. A. Deliyanni, E. N. Peleka and K. A. Matis, "Effect of Cationic Surfactant on Adsorption of Arsenates onto Akaganeite Nanocrystals," Separation science and Technology, Vol. 42, No. 5, 2007, pp. 993-1012. doi:10.1080/01496390701206306

[10] H. Khalaf, O. Bouras and V. Perrichon, "Synthesis and Characterization of Al-Pillared and Cationic Surfactant Modified Al-Pillared Algerian Bentonite," Microporous Materials, Vol. 8, No. 3-4, 1997, pp. 141-150.

[11] O. Agrawal, G. Sunita and V. K. Gupta, "A Sensitive Colorimetric Method for the Determination of Arsenic in Environmental and Biological Samples," Journal of Chinese Chemical Society, Vol. 46, No. 4, 1999, pp. 641-645.

[12] B. Ersoy and M. Çelik, "Effect of Hydrocarbon Chain Length on Adsorption of Cationic Surfactants onto Clinoptilolite," Clays Clay Minerals, Vol. 51, No. 2, 2003, pp. 172-180. doi:10.1346/CCMN.2003.0510207

[13] Z. Li and R. S. Bowman, "Retention of Inorganic Oxyanions by Organo-Kaolinite," Water Research, Vol. 35, No. 6, 2001, pp. 3771-3776. 